\title{
Seroconversion for West Nile and St. Louis encephalitis viruses among sentinel horses in Colombia
}

\author{
Salim Mattar ${ }^{1 /+}$, Nicholas Komar², Ginger Young², Jaime Alvarez ${ }^{1}$, Marco Gonzalez \\ 'Universidad de Córdoba, Instituto de Investigaciones Biológicas del Trópico, Córdoba, Colombia \\ ${ }^{2}$ Division of Vector-Borne Diseases, Centers for Disease Control and Prevention, Fort Collins, CO, USA
}

We prospectively sampled flavivirus-naïve horses in northern Colombia to detect West Nile virus (WNV) and St. Louis encephalitis virus (SLEV) seroconversion events, which would indicate the current circulation of these viruses. Overall, 331 (34.1\%) of the 971 horses screened were positive for past infection with flaviviruses upon initial sampling in July 2006. During the 12-month study from July 2006-June 2007, 33 WNV seroconversions and 14 SLEV seroconversions were detected, most of which occurred in the department of Bolivar. The seroconversion rates of horses in Bolivar for the period of March-June 2007 reached 12.4\% for WNV and 6.7\% for SLEV. These results comprise the first serologic evidence of SLEV circulation in Colombia. None of the horses sampled developed symptoms of encephalitis within three years of initial sampling. Using seroconversions in sentinel horses, we demonstrated an active circulation of WNV and SLEV in northern Colombia, particularly in the department of Bolivar. The absence of WNV-attributed equine or human disease in Colombia and elsewhere in the Caribbean Basin remains a topic of debate and speculation.

Key words: flavivirus - West Nile virus - St. Louis encephalitis virus - Colombia - equine

West Nile virus (WNV) has been spreading southward into the Caribbean basin and Latin America since 2001, reaching Mexico, Central America, Colombia, Venezuela and the Greater and Lesser Antilles within the last decade (Komar \& Clark 2006). WNV is a member of the Japanese encephalitis serogroup within the family Flaviviridae. Other members of this family found in South America include St. Louis encephalitis virus (SLEV), Rocio virus and Ilheus virus. These arboviruses are typically spread by Culex spp mosquitoes within the subgenus Culex, such as Culex (Culex) quinquefasciatus, the southern house mosquito. These mosquitoes are opportunistic feeders and often pass the viruses from their sylvatic or enzootic maintenance hosts to dead-end hosts, such as humans and horses (Pauvolid-Corrêa et al. 2010). Horses are exposed to numerous mosquito bites and may serve as sensitive sentinels for local arbovirus activity, which can be detected by screening for the novel production of specific virus-reactive antibodies ("seroconversion"). Horses infected with WNV may develop neurologic disease, sometimes leading to death, but most infections are subclinical and will only be detected through testing for seroconversion (Davidson et al. 2005).

Vaccines against WNV and Japanese encephalitis virus are available commercially to horse owners in some countries and the use of these vaccines results in seroconversion (Davidson et al. 2005, Hirota et al. 2010).

Financial support: COLCIENCIAS (414-2005, code 1112-04-18258), University of Cordoba

+ Corresponding author: mattarsalim@hotmail.com

Received 21 March 2011

Accepted 31 August 2011
Unvaccinated resident horses were the subject of a serosurvey in northern Colombia in 2005 that detected serologic evidence of past infections with both WNV and SLEV (Mattar et al. 2005). In the present study, we add to the knowledge of the epizootiology of flaviviruses in northern Colombia by prospectively sampling flavivirusseronegative horses to detect seroconversion events that would indicate current circulation of these viruses. The observed seroconversions in these sentinels presumably resulted from primary flavivirus infections. Thus, we also evaluated whether the primary flavivirus infections in these sentinel horses were more likely to be attributable to specific pathogens, i.e., WNV, SLEV or Ilheus virus, by the plaque-reduction neutralisation assay than the flavivirus-reactive sera from horses with unknown infection histories. This comparison, if it revealed a significant difference, would indicate the extent to which primary flavivirus infections in equines are differentiable in the flavivirus-transmission context of northern Colombia.

\section{MATERIALS AND METHODS}

Sentinel equines - Captive horses $(n=971)$ from 25 stables distributed among five departments of northern Colombia were selected for this study (Figure). The departments were Magdalena, Córdoba, Sucre, Bolivar and Atlántico. Initial blood samples were collected from horses by jugular venipuncture during July or August 2006 and follow-up blood samples were collected at approximately four-month intervals through July 2007. No horses had a previous history of flavivirus vaccination or travelled outside of the study region.

Serology - Serum samples were screened for flavivirus group-reactive antibodies using an epitope-blocking enzyme linked-immunosorbent assay (ELISA) that employs recombinant envelope protein from $\mathrm{WNV}$ as the target antigen and the monoclonal antibody 6B6C-1 (Blitvich et 


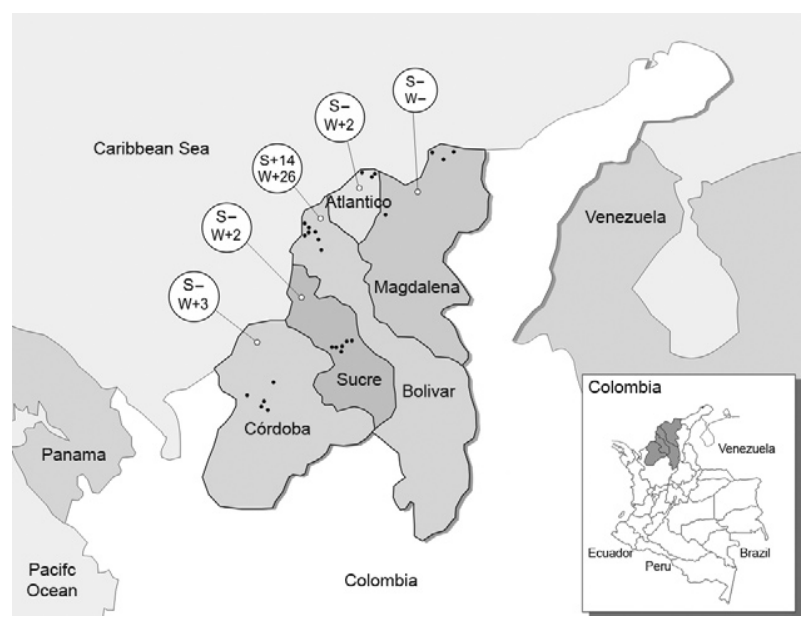

Location of equine sampling sites in northern Colombia is indicated by black dots. Circles indicate the number of seroconversions to St. Louis encephalitis virus (S) and West Nile virus (W) by department.

al. 2003). The samples that were positive by ELISA ( $\%$ inhibition of optical density $>30 \%$ ) were further confirmed using the comparative plaque-reduction neutralisation test (PRNT) (Beaty et al. 1995). The reference viruses used in these tests were Ilheus virus (Original), SLEV (75D90) and WNV (NY99-4132). Standard negative and positive controls were included in all assays. When determining whether a sample should be considered positive for neutralising antibodies to a specific virus, the sample's reciprocal $90 \%$ neutralisation titre was considered.

\section{RESULTS}

Overall, 331 (34.1\%) of the 971 horses screened were positive for past infection with flaviviruses upon initial sampling in July 2006 (Table I). Of these infections, only $23.3 \%$ could be assigned to specific aetiologies by PRNT. WNV and SLEV-neutralising antibodies were detected in $47(4.8 \%)$ and $30(3.1 \%)$ horses, respectively (Table II). In the three subsequent samples during the 12-month study, WNV seroconversion rates among flavivirus-naïve horses were $2.3 \%, 0.6 \%$ and $3.7 \%$, respectively; in total, 33 seroconversions were detected throughout the sampling area (Table II). The SLEV seroconversion rates were $0.5 \%, 0.4 \%$ and $2 \%$ and there were 14 seroconversions, all of which occurred in Bolivar. Bolivar experienced more WNV seroconversions $(n=26)$ than the other four departments combined $(n=7)$. The arbovirus seroconversion rates of horses in Bolivar for the period of March-June 2007 reached 12.4\% for WNV and $6.7 \%$ for SLEV.

To determine whether the sentinel horses that seroconverted were more likely to have identifiable infections relative to horses with unknown flavivirus infection histories, we compared the fraction of flavivirus-reactive sentinels that had identifiable virus-neutralising antibodies (47/253) to the same fraction $(77 / 331)$ in the seropositive horses detected at the beginning of the study and were consequently excluded as sentinels. The difference was not significant (left-tailed $\mathrm{p}=0.93$, Fisher's exact test).

No seroconversions were detected for Ilheus virus. None of the horses sampled developed symptoms of encephalitis within three years of the initial sampling.

\section{DISCUSSION}

Using seroconversions in sentinel horses, we clearly demonstrated the active circulation of WNV and SLEV in northern Colombia, particularly in the department of Bolivar. Interestingly, no apparent equine illness was detected among the 47 newly infected horses, suggesting a low risk of clinical infection $(<3 \%)$ for Colombian horses. This risk has been described as $20-40 \%$ in North American and European outbreaks (Komar 2000). Clinical SLEV infection in horses has not been described and therefore illness was not expected among the 14 horses newly infected with SLEV in our study. Our results comprise the first serologic evidence of SLEV circulation in Colombia.

In addition to the 47 horses that seroconverted due to infections with WNV and SLEV, 206 other sentinels seroconverted for flavivirus infection, but the aetiologic agent could not be determined by the PRNT as-

\section{TABLE I}

Detection of flavivirus-reactive antibodies in horses in July or August 2006 (sample 1) and subsequently at approximately four-month intervals until June 2007 among flavivirus-naïve horses stabled in five departments of northern Colombia

\begin{tabular}{lccccc}
\hline & $\begin{array}{c}\text { Sample 1 } \\
\text { Jul-Aug 2006 } \\
\text { Department }\end{array}$ & $\begin{array}{c}\text { Sample 2 } \\
\text { Sep-Oct 2006 } \\
\mathrm{n}(\%)\end{array}$ & $\begin{array}{c}\text { Sample 3 } \\
\text { Feb-Mar 2007 } \\
\mathrm{n}(\%)\end{array}$ & $\begin{array}{c}\text { Sample 4 } \\
\text { May-Jun 2007 } \\
\mathrm{n}(\%)\end{array}$ & $\begin{array}{c}\text { Total } \\
\text { seroconversions } \\
\mathrm{n}(\%)\end{array}$ \\
\hline Atlántico & $39 / 187(20.8)$ & $3 / 69(4.3)$ & $2 / 66(3)$ & $25 / 64(39.1)$ & $30 / 69(43.5)$ \\
Bolivar & $28 / 185(15.1)$ & $7 / 157(4.4)$ & $3 / 140(2.1)$ & $17 / 137(12.4)$ & $27 / 157(17.2)$ \\
Córdoba & $63 / 167(37.7)$ & $21 / 104(2)$ & $15 / 83(18.7)$ & $60 / 68(88.2)$ & $96 / 104(92.3)$ \\
Magdalena & $90 / 218(41.3)$ & $14 / 128(10.9)$ & $18 / 114(15.8)$ & $22 / 96(22.9)$ & $54 / 128(42.2)$ \\
Sucre & $111 / 214(51.9)$ & $6 / 103(5.8)$ & $15 / 97(15.5)$ & $25 / 82(30.5)$ & $46 / 103(44.7)$ \\
\hline Total & $331 / 971(34.1)$ & $51 / 561(9.1)$ & $53 / 509(10.4)$ & $149 / 456(32.7)$ & $253 / 561(45.1)$ \\
\hline
\end{tabular}


say. These horses may have been infected with multiple flaviviruses, resulting in cross-reactive antibodies that inhibited the identification of the infecting pathogen. Alternatively, these horses may have been infected with an unknown flavivirus that lead to the development of antibodies that cross-reacted with WNV and SLEV. Finally, they could have been infected with both WNV and SLEV. Thus, it is possible that our serologic techniques grossly underestimated the true equine infection rates due to these closely related viruses. This situation implies that serologic evidence for flavivirus infections in horses should not be used for quantitative comparisons between localities, only within localities (i.e., to demonstrate increases or decreases in flavivirus transmission activity within a sampling site over time).

Both WNV and SLEV cause focal outbreaks of significant public health concern in USA and presumably cause similar disease in Colombia, although human cases of encephalitis due to these zoonotic flaviviruses have not been reported in Colombia. These mosquito-bourne encephalitides should be included in the differential diagnosis of human encephalitis in Colombia and WNV should be considered a possible cause of fatal neurologic illness of horses and birds and possibly other domestic and wild vertebrates in Colombia. If these viruses are indeed causing disease in Colombia, we have provided a potential model for tracking their activity over space and time through the use of sentinel horses. In the Caribbean area of Colombia, the extensive cattle system favours close contact among livestock, including horses and the local sylvatic fauna and vector populations. Thus, equines of the Caribbean basin should be considered as candidate sentinels for the detection of flavivirus circulation in the area.

In our study, we observed a major focus of WNV activity in the department of Bolivar during the period of March-June 2007. During this same period, intense WNV activity in sentinel animals (chickens) was observed elsewhere in the Caribbean Basin, in eastern Puerto Rico (Barrera et al. 2010) and in the department of Izabal, Guatemala (Centers for Disease Control and Prevention, unpublished observations). Human and equine disease cases were absent in all three locations. The apparently reduced virulence of WNV in the Caribbean basin countries remains a topic of debate and speculation.

\section{ACKNOWLEDGEMENTS}

To Ader Aleman, for technical assistance.

\section{REFERENCES}

Barrera R, Mackay A, Amador M, Vásquez J, Smith J, Díaz A, Acevedo V, Caban B, Hunsperger EA, Muñoz-Jordán JL 2010. Mosquito vectors of West Nile virus during an epizootic outbreak in Puerto Rico. J Med Entomol 47: 1185-1195.

Beaty BJ, Calisher CH, Shope RE 1995. Arboviruses. In EH Lennette, DA Lennette, ET Lennette (eds.), Diagnostic procedures for viral, rickettsial and chlamydial infections, 7 th ed., American Public Health Association, Washington DC, p. 189-212.

Blitvich BJ, Marlenee NL, Hall RA, Calisher CH, Bowen RA, Roehrig JT, Komar N, Langevin SA, Beaty BJ 2003. Epitope-blocking enzyme-linked immunosorbent assays for the detection of serum 
antibodies to West Nile virus in multiple avian species. J Clin Microbiol 41: 1041-1047.

Davidson AH, Traub-Dargatz JL, Rodeheaver RM, Ostlund EN, Pedersen DD, Moorhead RG, Stricklin JB, Dewell RD, Roach SD, Long RE, Albers SJ, Callan RJ, Salman MD 2005. Immunologic responses to West Nile virus in vaccinated and clinically affected horses. J Am Vet Med Assoc 226: 240-245.

Hirota J, Nishi H, Matsuda H, Tsunemitsu H, Shimiz S 2010. Crossreactivity of Japanese encephalitis virus-vaccinated horse sera in serodiagnosis of West Nile virus. J Vet Med Sci 72: 369-372.

Komar N 2000. West Nile viral encephalitis. Off Int Epiz Sci Tech Rev 19: 166-176.
Komar N, Clark G 2006. West Nile virus activity in Latin America and the Caribbean. Rev Panam Salud Publica 19: 112-117.

Mattar S, Edwards E, Laguado J, González M, Alvarez J, Komar N 2005. West Nile virus infection in Colombian horses. Emerg Infect Dis 11: 1497-1498.

Pauvolid-Corrêa A, Neto Tavares F, Veiga da Costa E, Marcicano Burlandy F, Murta M, Oliveira Pellegrin A, Furlan Nogueira M, Elias da Silva E 2010. Serologic evidence of the recent circulation of Saint Louis encephalitis virus and high prevalence of equine encephalitis viruses in horses in the Nhecolândia sub-region in South Pantanal, Central-West Brazil. Mem Inst Oswaldo Cruz 105: 829-833. 